\title{
PENGARUH INTEGRITAS DAN KREATIVITAS KONSULTAN PAJAK TERHADAP KEPATUHAN WAJIB PAJAK
}

\author{
Djuliana Katuuk $^{1}$, Hendrik Manossoh ${ }^{2}$, Stanley Kho Walandouw ${ }^{3}$ \\ ${ }^{123}$ Fakultas Ekonomi dan Bisnis, Jurusan Akuntansi, Universitas Sam Ratulangi, Jl. Kampus Bahu, Manado, \\ 95115, Indonesia \\ E-mail : djuliananne@gmail.com
}

\begin{abstract}
Taxes have a major influence on state revenues. With the tax system in Indonesia is considered to have a high complexity of the number of regulations that often change from time to time make taxpayers need other parties to conduct self assessment system that is tax consultant. Tax consultants as professionals who offer services in the field of taxation should have the creativity in this case solves the problem of taxation of clients but cannot be separated from it must be integrity according to ethical principles.The purpose of this study is to determine the influence of the integrity and creativity of tax consultants simultaneously and partially to taxpayer compliance. Respondents in this study are taxpayers users of tax consultant services in Manado. Analytical technique in this study using multiple regression analysis using quantitative data with survey approach using questionnaires research instrument with the sample used as much as 48 respondents. Based on the statistical test, the results of this study indicate that the tax consultant's integrity and creativity of tax consultants simultaneously and partially have an influence on taxpayer compliance. So it can be concluded Tax Consultant has influence in improving taxpayer compliance.
\end{abstract}

Keywords : Integrity, Creativity, Tax Consultant, Taxpayer Compliance

\section{PENDAHULUAN}

\subsection{Latar Belakang}

Dalam pemenuhan kewajiban perpajakan yang sangat kompleks, salah satu pihak yang dinilai lebih memahami dan mendalami tata cara pelaksanaan kewajiban perpajakan adalah konsultan pajak. Peran konsultan pajak disini diyakini dapat memfasilitasi wajib pajak dalam memenuhi kewajiban perpajakannya. Dengan adanya peran Konsultan Pajak ini ada biaya yang timbul dalam komponen biaya kepatuhan wajib pajak yang dikeluarkan oleh wajib pajak. Adapun hasil penelitian dari (Hadi Sugiyanto, 2015) Konsultan Pajak memiliki peran ideal dalam membantu Direktorat Jenderal Pajak dalam mengedukasi Wajib Pajak ditengah kecilnya kepercayaan masyarakat kepada petugas pajak dan Self Assesment sistem dalam menjalankan kewajiban perpajakan yang dilakukan Wajib Pajak.

Menurut Puspita Wulandari, Sekjen Komwas Perpajakan," Profesi ideal konsultan pajak harus memiliki independensi, profesionalisme, dan integritas dalam menjalankan bisnis industrinya". Konsultan pajak memiliki fungsi tax consulting, tax settlement, tax mediation, attorney at tax law, dan agent of tax awareness. Oleh karena itu peran konsultan pajak sangat penting dan dibutuhkan bagi negara untuk ikut serta meningkatkan kepatuhan wajib pajak.

Salah satu yang diatur dalam prinsip etika adalah integritas konsultan dalam menjalankan tugasnya. Integritas adalah kepatuhan tanpa kompromi untuk kode nilai-nilai moral, dan menghindari penipuan kemanfaatan kepalsuan, atau kedangkalan apapun. Pentingnya integritas berasal dari ide bahwa profesi adalah "panggilan" dan membutuhkan professional untuk fokus pada gagasan bahwa mereka melakukan pelayanan publik. Integritas mempertahankan prestasi yang tinggi dan melakukan kompetensi yang berarti memiliki kecerdasan, pendidikan, pelatihan untuk dapat nilai tambah melalui kinerja (Lina Herlina : 2014). Salah satu ciri profesionalisme lain yang disepakati banyak kalangan ialah memiliki 
kreativitas dan prestasi yang meyakinkan. Kreativitas konsultan dibutuhkan guna memotivasi kesadaran wajib pajak sehingga wajib pajak meningkatkan kepatuhan membayar pajak.

Peranan konsultan pajak cukup mampu berkontribusi terhadap kepatuhan wajib pajak. Namun tentu saja hal ini perlu dibuktikan lebih lanjut melalui penelitian. Penelitian serupa pernah dilakukan oleh Devos (2012) yang meneliti mengenai hubungan pengaruh konsultan pajak terhadap tingkat kepatuhan wajib pajak di Australia. Penelitian ini merupakan pengembangan dari penelitian sebelumnya yang dilakukan oleh Lusiana Sutanto dan Elisa Tjondro (2013) tentang persepsi wajib pajak yang ada di surabaya terhadap tipe konsultan pajak, dan Imam Fauzhi, Srikandi Kumadji, dan Otto Budihardjo (2015) tentang pengaruh kualitas konsultan pajak dan pengetahuan pajak terhadap kepatuhan wajib pajak di Surabaya. Dari sejumlah penelitian yang membahas pengaruh konsultan pajak terhadap kepatuhan wajib pajak masih sangat jarang ditemukan yang meneliti tentang wajib pajak yang ada di manado.

Berdasarkan uraian diatas penulis tertarik untuk mengkaji lebih jauh tentang pengaruh integritas dan kreativitas konsultan pajak dalam meningkatkan kepatuhan wajib pajak, apakah menurut wajib pajak ada pengaruh atau tidak. Sehingga penelitian ini diberi judul "Pengaruh Integritas dan Kreativitas Konsultan Pajak terhadap Kepatuhan Wajib Pajak"

\subsection{Tujuan Penelitian}

Adapun tujuan yang ingin dicapai dalam penelitian ini adalah.

1. Untuk mengetahui pengaruh integritas dan kreativitas konsultan pajak secara simultan terhadap kepatuhan wajib pajak.

2. Untuk mengetahui pengaruh integritas konsultan pajak secara parsial terhadap kepatuhan wajib pajak.

3. Untuk mengetahui pengaruh kreativitas konsultan pajak secara parsial terhadap kepatuhan wajib pajak.

\section{TINJAUAN PUSTAKA}

\subsection{Konsultan Pajak}

Sesuai dengan Peraturan Meneteri Keuangan Republik Indonesia Nomor 111/PMK.03/2014 tentang Konsultan Pajak Pasal 1, yang dimaksud dengan Konsultan Pajak adalah orang yang memberikan jasa konsultasi perpajakan kepada Wajib Pajak dalam rangka melaksanakan hak dan memenuhi kewajiban perpajakannya sesuai dengan peraturan perundang-undangan perpajakan.

\subsection{Integritas}

Menurut Mulyadi (2007:145) dalam Herlina (2014) Integritas adalah kemampuan orang untuk mewujudkan apa yang telah diucapkan atau dijanjikan oleh orang tersebut menjadi suatu kenyataan.

\subsection{Kreativitas}

Kreativitas menurut Suryana (2003) dalam penelitian Ernani Hadiyati (2011:10) menyatakan bahwa: "Kreativitas adalah berpikir sesuatu yang baru. Kreativitas sebagai kemampuan untuk mengembagakan ide - ide baru dan untuk menemukan cara-cara baru dalam memecahkan persoalan dalam mempengaruhi orang lain dan menghadapi peluang”.

\subsection{Kepatuhan Wajib Pajak}

Kepatuhan perpajakan adalah suatu keadaan dimana wajib pajak patuh dan mempunyai kesadaran dalam memenuhi kewajiban perpajakan. Devano (2006) dalam Charoline (2014) mengemukakan kepatuhan dan kesadaran pemenuhan kewajiban perpajakan tercermin dalam situasi (1) Wajib Pajak berusaha memahami semua ketentuan peraturan 
perundang-undangan perpajakan, (2) Wajib Pajak mengisi formulir pajak dengan lengkap dan jelas, (3) Wajib Pajak menghitung jumlah pajak yang terutang dengan benar, dan (4) Wajib Pajak membayar pajak yang terutang tepat pada waktunya.

\subsection{Hipotesis}

$\mathrm{H}_{\mathrm{o}} 1$ : Integritas Konsultan Pajak diduga tidak berpengaruh secara parsial terhadap Kepatuhan Wajib Pajak.

$\mathrm{H}_{\mathrm{a}} 1$ : Integritas Konsultan Pajak diduga berpengaruh secara parsial terhadap Kepatuhan Wajib Pajak.

$\mathrm{H}_{\mathrm{o}} 2$ : Kreativitas Konsultan Pajak diduga tidak berpengaruh secara parsial terhadap Kepatuhan Wajib Pajak.

$\mathrm{H}_{\mathrm{a}} 2$ : Kreativitas Konsultan Pajak diduga berpengaruh secara parsial terhadap Kepatuhan Wajib Pajak.

$\mathrm{H}_{\mathrm{o}} 3$ : Integritas dan Kreativitas Konsultan Pajak diduga tidak berpengaruh secara simultan terhadap Kepatuhan Wajib Pajak.

$\mathrm{H}_{\mathrm{a}} 3$ : Integritas dan Kreativitas Konsultan Pajak diduga berpengaruh secara simultan terhadap Kepatuhan Wajib Pajak.

\subsection{Penelitian Terdahulu}

Penelitian yang dilakukan oleh Ken Devos (2012) menunjukkan bahwa ada hubungan signifikan secara statistik antara kebutuhan untuk melibatkan para profesional pajak dan perilaku kepatuhan umumnya. Peneltian yang dilakukan oleh Imam Fauzhi, dkk (2015) menunjukkan Kualitas jasa Konsultan Pajak dan pengetahuan pajak berpengaruh secara bersama-sama signifikan terhadap kepatuhan wajib pajak. Sedangkan, Penelitian yang dilakukan oleh Eko Sumberjaya dan Anton Arisman (2013) menyatakan peran konsultan pajak tidak mempengaruhi kepatuhan wajib pajak UMKM di Kota Palembang. Dalam penelitian Sutanto Lusiana dan Elisa Tjondro (2013) menunjukkan bahwa adanya korelasi positif kuat antara persepsi wajib pajak dalan menggunakan konsultan pajak. Penlitian yang dilakukan oleh Lina Herlina (2014) menunjukkan Integritas dan kompetensi auditor memberikan pengaruh positif signifikan terhadap kualitas audit. Penelitian yang dilakukan oleh Edi Waluyo (2013) menyatakan bahwa kreativitas guru berpengaruh positif dan signifikan terhadap hasil belajar siswa.

\section{METODE PENELITIAN}

\subsection{Jenis dan sumber data}

Penelitian ini menggunakan metode penelitian kuantitatif dengan pendekatan survey. Menurut Sugiyono (2015:14), metode penelitian kuantitatif merupakan metode penelitian yang berlandaskan pada filsafat positivisme, digunakan untuk meneliti pada populasi atau sampel tertentu, teknik pengambilan sampel pada umumnya dilakukan secara random, pengumpulan data menggunakan instrumen penelitian, analisis data bersifat kuantitatif/statistik dengan tujuan untuk menguji hipotesis yang telah ditetapkan. Menurut Sugiyono (2013:6) Pendekatan survey digunakan untuk mendapatkan data tertentu yang alamiah, tetapi peneliti melakukan perlakuan dalam pengumpulan data, misalnya dengan kuesioner, test, wawancara terstruktur dan sebagainya.

\subsection{Sampel dan teknik pengambilan sampel}

Sampel merupakan bagian dari populasi yang ingin diteliti; dipandang sebagai suatu pendugaan terhadap populasi, namun bukan populasi itu sendiri. Sampel dianggap sebagai perwakilan dari populasi yang hasilnya mewakili keseluruhan gejala yang diamati (wikipedia.org). Teknik pengambilan sampel yang digunakan dalam penelitian ini adalah 
Cluster random sampling, yaitu memilih sejumlah responden dari wilayah tertentu sampai batas data yang diinginkan terpenuhi (Suharsimi 2013:33). Dan dalam penelitian ini sampel yang digunakan berjumlah 48 responden yang disebarkan di Kantor Konsultan Pajak Drs.Tennie W.B. Londah dan Kantor Konsultan lain.

\subsection{Metode analisis}

Metode yang digunakan untuk menganalisis data instrumen penelitian berupa kuesioner adalah uji kualitas data dengan melakukan uji validitas dan uji realiabilitas. Selanjutnya agar hasil perhitungan dapat diinterpretasikan dengan akurat dilakukan uji asumsi klasik yang meliputi uji normalitas, uji multikolonieritas, dan uji heterokedastisitas. Terakhir, dilakukan pengujian terhadap model regresi linear berganda yang meliputi uji koefisien determinasi $\left(\mathrm{R}^{2}\right)$, uji signifikan simultan (uji F), dan uji t. Semua uji analisis ini dilakukan dengan bantuan software SPSS Statistic versi 23.

\section{HASIL ANALISIS DAN PEMBAHASAN}

\subsection{Hasil analisis}

Data yang digunakan dalam penelitian ini adalah data dari hasil penelitian yang diperoleh dari kuesioner ke Kantor Konsultan Pajak Drs. Tennie Londah sebanyak 30 kuesioner dan yang kembali 28 kuesioner, serta ke klien kantor konsultan lain sebanyak 20 kuesioner sehingg jumlah responden pada penelitian ini adalah sebanyak 48 responden.

Dengan hasil nilai rata-rata sebesar 3,97 untuk variabel integritas konsultan pajak yang berarti rata-rata wajib pajak memilih poin 4 yaitu setuju sehingga dikatakan baik. Dan hasil nilai rata-rata sebesar 4,02 untuk variabel kreativitas konsultan pajak yang berarti ratarata wajib pajak memilih poin 4 yaitu setuju sehingga dikatakan baik. Dan hasil nilai rata-rata sebesar 3,92 untuk variabel kepatuhan wajib pajak yang berarti rata-rata wajib pajak memilih poin 4 yaitu setuju sehingga dikatakan baik.

\section{Uji Kualitas Data}

Untuk melihat apakah data yang diperoleh dari kuesioner yang dibagikan dapat dipercaya dilakukan uji validitas dan uji reliabilitas. Penelitian ini telah lulus uji validitas dan reliabilitas.

\section{Uji Asumsi Klasik}

Agar hasil penelitian dapat diinterpretasikan dengan akurat maka dilakukan uji asumsi klasik. Penelitian ini telah lulus uji normalitas, multikolonieritas, serta heterokedastisitas.

\section{Uji Hipotesis}

Model Summary ${ }^{b}$

\begin{tabular}{|c|r|r|r|r|r|}
\hline Model & $\mathrm{R}$ & $\mathrm{R}$ Square & $\begin{array}{c}\text { Adjusted R } \\
\text { Square }\end{array}$ & $\begin{array}{c}\text { Std. Error of the } \\
\text { Estimate }\end{array}$ & Durbin-Watson \\
\hline 1 & $.793^{\mathrm{a}}$ & .629 & .612 & 1.848 & 2.306 \\
\hline
\end{tabular}

a. Predictors: (Constant), Kreativitas Konsultan Pajak, Integritas Konsultan Pajak

b. Dependent Variable: Kepatuhan Wajib Pajak

Sumber: Hasil Pengelolaan Data Primer dengan Alat bantu SPSS versi 23.

Pada tabel diatas terlihat bahwa koefisien determinasi yang disesuaikan (Adjusted $R$ Square) sebesar 0,612 memberi pengertian bahwa variasi yang terjadi pada variabel Y (Kepatuhan Wajib Pajak) adalah sebesar 61,2 \% ditentukan oleh variabel Integritas dan Kreativitas Konsultan Pajak dan selebihnya sebesar 38,8 \% (100\%-61,2\%). 


\section{Uji T}

Coefficients $^{\mathrm{a}}$

\begin{tabular}{|c|r|r|r|r|r|}
\hline \multirow{2}{*}{ Model } & \multicolumn{2}{|c|}{$\begin{array}{c}\text { Unstandardized } \\
\text { Coefficients }\end{array}$} & $\begin{array}{c}\text { Standardized } \\
\text { Coefficients }\end{array}$ & \multirow{2}{*}{$\mathrm{t}$} & \multirow{2}{*}{ Sig. } \\
\cline { 2 - 5 } & \multicolumn{1}{|c|}{$\mathrm{B}$} & \multicolumn{1}{c|}{ Std. Error } & \multicolumn{1}{c|}{ Beta } & & \\
\hline (Constant) & 2.235 & 2.062 & & 1.084 & .284 \\
IntegritasKonsultanPajak & .607 & .166 & .535 & 3.648 & .001 \\
KreativitasKonsultanPajak & .264 & .129 & .300 & 2.043 & .047 \\
\hline
\end{tabular}

a. Dependent Variable: KepatuhanWajibPajak

Sumber : Hasil Pengelolaan Data Primer dengan Alat Bantu SPSS versi 23

\section{H1 = Integritas Konsultan Pajak berpengaruh terhadap Kepatuhan Wajib Pajak}

Variabel independen Integritas Konsultan Pajak $\left(\mathrm{X}_{1}\right)$ memperlihatkan bahwa variabel Integritas memiliki nilai signifikan sebesar 0,001 lebih kecil dari nilai alpha 0,05 $(0,001<$ 0,05) dengan $t_{\text {hitung }}(3.648)>$ nilai $t_{\text {tabel }}$ (1.084). Untuk itu dapat dikatakan bahwa $\mathrm{Ha}_{1}$ diterima dan $\mathrm{Ho}_{1}$ ditolak sehingga dapat disimpulkan bahwa variabel Integritas Konsultan Pajak memiliki pengaruh secara parsial terhadap Kepatuhan Wajib Pajak.

\section{H2 = Kreativitas Konsultan Pajak berpengaruh terhadap Kepatuhan Wajib Pajak}

Variabel independen Kreativitas Konsultan Pajak $\left(\mathrm{X}_{2}\right)$ memperlihatkan bahwa variabel Kreativitas Konsultan Pajak memiliki nilai signifikan sebesar 0,047 lebih kecil dari nilai alpha $0,05(0,047<0,05)$ dengan $t_{\text {hitung }}(2.043)>$ nilai $t_{\text {tabel }}(1.084)$. Untuk itu dapat dikatakan bahwa $\mathrm{Ha}_{2}$ diterima dan $\mathrm{Ho}_{2}$ ditolak sehingga dapat disimpulkan bahwa variabel Kreativitas Konsultan Pajak memiliki pengaruh secara parsial terhadap Kepatuhan Wajib Pajak.

Berdasarkan tabel persamaan regresi linear berganda dapat ditulis sebagai berikut :
Y : Kepatuhan Wajib Pajak
a : Konstanta
$\mathrm{b}_{1}, \mathrm{~b}_{2} \quad$ : Koefisien regresi berganda
$\mathrm{X}_{1} \quad$ : Integritas Konsultan Pajak
$\mathrm{X}_{2} \quad$ : Kreativitas Konsultan Pajak
e : Error

$$
Y=5,926+0,374 X_{1}+0,324 X_{2}+2,632
$$

Uji F

ANOVA $^{\mathrm{a}}$

\begin{tabular}{|c|c|c|c|c|c|c|}
\hline & Model & Sum of Squares & $\mathrm{df}$ & Mean Square & $\mathrm{F}$ & Sig. \\
\hline & Regression & 259.878 & 2 & 129.939 & 38.068 & $.000^{\mathrm{b}}$ \\
\hline 1 & Residual & 153.602 & 45 & 3.413 & & \\
\hline & Total & 413.479 & 47 & & & \\
\hline
\end{tabular}

a. Dependent Variable: KepatuhanWajibPajak

b. Predictors: (Constant), KreativitasKonsultanPajak, IntegritasKonsultanPajak

Sumber : Hasil Pengelolaan Data Primer dengan Alat bantu SPSS versi 23.

H3 = Integritas dan Kreativitas Konsultan Pajak berpengaruh terhadap Kepatuhan Wajib Pajak 
Dalam model ANOVA dapat diperoleh $\mathrm{F}$ hitung sebesar 38.068 dengan tingkat signifikan 0.000. Oleh karena tingkat signifikan tersebut lebih kecil daripada 0,05 maka variabel integritas dan kreativitas Konsultan Pajak secara simultan atau secara bersama-sama berpengaruh signifikan terhadap variabel dependen yaitu Kepatuhan Wajib Pajak.

\subsection{Pembahasan}

\section{Pengaruh Integritas Konsultan Pajak terhadap Kepatuhan Wajib Pajak}

Berdasarkan hasil olah data dengan SPSS menunjukan Integritas Konsultan Pajak berpengaruh secara parsial terhadap kepatuhan wajib pajak karena dalam melakukan tugasnya sebagai bagian dari pemerintah dalam menghimpun pajak dari masyarakat ketika dilaksanakan dengan benar dan jujur akan mendorong wajib pajak sebagai kliennya akan membayar pajak secara benar dan jujur. Hal ini sesuai dengan penelitian yang dilakukan oleh M. Yusuf (2014) yaitu, Integritas berpengaruh signifikan positif terhadap kualitas hasil kerja auditor pada BPKP Perwakilan Riau.

\section{Pengaruh Kreativitas Konsultan Pajak terhadap Kepatuhan Wajib Pajak}

Berdasarkan hasil olah data dengan SPSS menunujukan Kreativitas berpengaruh secara parsial terhadap kepatuhan wajib pajak dengan adanya Kreativitas dari konsultan pajak dalam membuat, menghitung, dan melaporkan pajak dari wajib pajak membantu wajib pajak membayar pajak dalam hal ini jumlah yang disetorkan dan waktu penyetoran yang sesuai tanpa melanggar peraturan perpajakan yang berlaku. Hasil penelitian ini mendukung hasil penelitian yang dilakukan oleh Edi Waluyo (2013) yang menyatakan kreativitas guru berpengaruh positif dan signifikan terhadap hasil belajar siswa.

Pengaruh Integritas dan Kreativitas Konsultan Pajak terhadap Kepatuhan Wajib Pajak

Berdasarkan hasil penelitian uji $\mathrm{F}$ dapat dilihat bahwa secara simultan (bersama-sama) variabel Integritas Konsultan Pajak $\left(\mathrm{X}_{1}\right)$ dan Kreativitas Konsultan Pajak $\left(\mathrm{X}_{2}\right)$ berpengaruh terhadap Kepatuhan Wajib Pajak. Konsultan Pajak umumnya melihat peran mereka sebagai bagian dari pembayar pajak dan perwakilan dari pemerintah. Artinya konsultan pajak percaya bahwa mereka ada untuk melayani klien mereka, tetapi juga untuk bertindak sebagai agen untuk otoritas dalam mempromosikan kepatuhan (Ken Devos : 2013). Sesuai dengan penelitian yang dilakukan Hadi Sugianto (2015) Profesi konsultan harus mampu menempatkan diri sebagai agen pemerintah untuk membantu penerimaan pajak dan mengkritisi aturan perpajakan disisi lain mereka juga sebagai representasi Wajib Pajak. Peranan konsultan yang begitu dilematis memberikan persepsi terhadap masyarakat akan peranan mereka, untuk menjaga independensi dan profesionalisme Konsultan Pajak telah memiliki kode etik yang mereka gunakan untuk melaksanakan praktik yang benar sehingga menjadi mitra yang baik bagi Direktorat Jenderal Pajak yang memiliki fungsi yang sama sebagai agen pemerintah dalam meningkatkan penerimaan pajak.

\section{KESIMPULAN DAN SARAN}

\subsection{Kesimpulan}

Dari hasil penelitian yang telah dilakukan atas variabel Integritas Konsultan Pajak, Kreativitas Konsultan Pajak dan Kepatuhan Wajib Pajak dengan melakukan studi pada wajib pajak yang menggunakan jasa Konsultan Pajak di Manado, maka dapat ditarik kesimpulan sebagai berikut :

1. Secara simultan Integritas dan Kreativitas Konsultan Pajak mempunyai pengaruh yang signifikan terhadap Kepatuhan Wajib Pajak yang dibuktikan dengan program SPSS 23,0 for windows dapat diketahui $\mathrm{F}$ hitung sebesar 38,068 dengan sig. sebesar 0,000 ( $\mathrm{p}<0,05$ ). Sedangkan sumbangan kontribusi variabel integritas dan kreativitas konsultan pajak terhadap kepatuhan wajib pajak sebesar 0,612 yang berarti bahwa 
kedua variabel tersebut memberikan kontrtibusi pada variabel kepatuhan wajib pajak sebesar $61,2 \%$, sedangkan sisanya sebesar $38,8 \%$ dipengaruhi oleh varian lain diluar model penelitian yang tidak termasuk dalam batasan penelitian ini.

2. Integritas Konsultan Pajak berpengaruh signifikan secara parsial terhadap Kepatuhan Wajib Pajak. Hal ini berdasarkan hasil pengujian dengan program SPSS 23,0 for windows dapat diketahui nilai $t_{\text {hitung }}$ sebesar 3,648 dengan sig. $\mathrm{t}$ sebesar 0,001 ( $\mathrm{p}<$ $0,05)$.

3. Kreativitas Konsultan Pajak berpengaruh signifikan secara parsial terhadap Kepatuhan Wajib Pajak. Hal ini berdasarkan hasil pengujian dengan program SPSS 23,0 for windows dapat diketahui nilai $t_{\text {hitung }}$ sebesar 2,043 dengan sig. $\mathrm{t}$ sebesar 0,047 ( $\mathrm{p}<$ $0,05)$.

\subsection{Saran}

Berdasarkan hasil penelitian dan pembahasan di atas, maka penulis memberikan saran sebagai berikut:

1. Kepada semua Kantor Konsultan Pajak di Manado untuk terus menjaga integritas dan meningkatkan kreativitasnya dalam menangani urusan perpajakan klien karena akan meningkatkan kepatuhan wajib pajak. Meningkatnya kepatuhan wajib pajak akan membantu Direktorat Jenderal Pajak (DJP) dalam mengelola pajak pusat.

2. Kepada Pemerintah dalam hal ini Kantor Direktorat Jenderal Pajak (DJP) untuk lebih meningkatkan kerja sama dengan Kantor-Kantor Konsultan Pajak karena dengan adanya kerja sama yang baik maka semakin menigkatkan kepatuhan wajib pajak.

3. Kepada peneliti selanjutnya yang akan melakukan penelitian yang sama untuk menambah variabel lain yang serupa dengan penelitian ini yang belum dimasukkan dalam penelitian ini.

\section{DAFTAR PUSTAKA}

Budileksmana, Antariksa, 2015, "Manfaat dan Peranan Konsultan Pajak dalam Era Self Assesment Perpajakan" Jurnal Akuntansi dan Investasi Vol. 1 No.2 hal:77-84. http://journal.umy.ac.id/index.php/ai/article/view/499, diunduh pada 26 Februari 2017.

Devos, Ken. 2012. The Impact of Tax Professionals Behaviour of Australian Individual Taxpayers. Revenue Law Journal. Volume 22.

Fauzhi, I., Kumadji, S, \& Budihardjo O, 2015, "Pengaruh Kualitas Jasa Konsultan Pajak dan Pengetahuan Pajak Terhadap Kepatuhan Wajib Pajak" Jurnal Administrasi Bisnis Perpajakan (JAB) Vol. 4 No. 1 Maret 2015. http://perpajakan.studentjournal.ub.ac.id

Ghozali, Imam, 2016. Desain Penelitian Kuantitatif dan Kualitatif untuk Akuntansi Bisnis. Cetakan ke-5, Semarang : Penerbit Yoga Pratama

Herlina, Lina, 2014, "Pengaruh Integritas dan Kompetensi Auditor terhadap Kualitas Audit" Jurnal Ekonomi Akuntansi Universitas Komputer Indonesia, di unduh pada 10 Februari 2017.

IKPI, Jumat, 13 September 2013 - 19:11, "Konsultan Pajak Harus Berkontirbusi Meningkatkan Kepatuhan Wajib Pajak" tersedia di http://www.pajak.go.id/content/news/konsultan-pajak-harus-berkontribusimeningkatkan-kepatuhan-wajib-pajak, tanggal akses : 27 februari 2017

Juwono, Onny \& Wangsadinata, Yuliana. 2010.'Kreativitas, Gaya Kepemimpinan dan Kompetensi dalam Membentuk Kepuasan Kerja Karyawan. Journal The WINNERS, Vol.11 No.1, Maret 2010:55-65. 
Kurniawan, Ciska \& Sadjiarto, Arja. 2013. "Pemahaman Kode Etik Konsultan Pajak Mengenai Hubungan dengan Wajib Pajak oleh Konsultan Pajak di Surabaya". Tax and Accounting Review Vol.1 No.1 2013.

Mardiasmo. 2016. Perpajakan. Edisi terbaru, Yogyakarta : Penerbit Andi.

Muljono, Djoko \& Baruni Wicaksono. 2009. Akuntansi Pajak Lanjutan, Yogyakarta : Penerbit ANDI.

Rahman Arif. 2013. Panduan Akuntansi dan Perpajakan. Cetakan Pertama, Jakarta : Penerbit Transmedia Pustaka

Rapat kerja pemerintah dengan Komisi XI Dewan Perwakilan Rakyat (DPR) di Senayan, Jakarta pada Rabu malam (12/10), 13 October 2016 - 09:38, “Akhir Triwulan III-2016, Realisasi Pendapatan Negara Capai 60,5 Persen" http://kemenkeu.go.id/Berita/akhirtriwulan-iii-2016-realisasi-pendapatan-negara-capai-605-persen tanggal akses : 27 Februari 2017

Sakurai, Yuka \& Braithwaite, Valeri. 2001. Taxpayers Perception of Ideal Tax Adviser: Playing Safe or Saving Dollars?. Working Paper No.5

Sugiyono. 2013. Metode Penelitian Kuantitatif, Kualitatif dan R\&D. Cetakan ke-19. Jogjakarta: Penerbit Alfabeta

Sutanto, Lusiana \& Tjondro, Elisa, 2013,'Persepsi Wajib Pajak Terhadap Konsultan Pajak dan Preferensi Wajib Pajak dalam memilih Konsultan Pajak : Honest Consultant, Creative Consultant, Dan Caution Consultant" Tax \& Accounting Review, Vol 3, No.2,2013

Waluyo. 2013. Perpajakan Indonesia. Edisi 11 buku 1, Jakarta : Penerbit Salemba Empat 